\title{
The role of the genetic counsellor: a systematic review of research evidence
}

\author{
Heather Skirton ${ }^{\star, 1}$, Christophe Cordier ${ }^{2}$, Charlotta Ingvoldstad ${ }^{3}$, Nicolas Taris $^{2}$ and Caroline Benjamin ${ }^{4}$ \\ In Europe, genetic counsellors are employed in specialist genetic centres or other specialist units. According to the European \\ Board of Medical Genetics, the genetic counsellor must fulfil a range of roles, including provision of information and facilitation \\ of psychosocial adjustment of the client to their genetic status and situation. To evaluate the extent to which genetic \\ counsellors fulfil their prescribed roles, we conducted a systematic review of the published relevant scientific evidence. \\ We searched five relevant electronic databases (Medline, CINAHL, SocIndex, AMED and Psychlnfo) using relevant search terms \\ and handsearched four subject-specific journals for research-based papers published in English between 1 January 2000 and \\ 30 June 2013. Of 419 potential papers identified initially, seven satisfied the inclusion criteria for the review. Themes derived \\ from the thematic analysis of the data were: (i) rationale for genetic counsellors to provide care, (ii) appropriate roles and \\ responsibilities and (iii) the types of conditions included in the genetic counsellor caseload. The findings of this systematic \\ review indicate that where genetic counsellors are utilised in specialist genetic settings, they undertake a significant workload \\ associated with direct patient care and this appears to be acceptable to patients. With the burden on genetic services, there is \\ an argument for the increased use of genetic counsellors in countries where they are under-utilised. In addition, roles \\ undertaken by genetic counsellors in specialist genetic settings could be adapted to integrate genetic counsellors into multi- \\ disciplinary teams in other specialisms.
}

European Journal of Human Genetics (2015) 23, 452-458; doi:10.1038/ejhg.2014.116; published online 11 June 2014

\section{INTRODUCTION}

Although the term 'genetic counselling' was coined by Sheldon Reed in $1947,{ }^{1}$ the genetic counselling profession is relatively young in comparison with medicine and nursing. Although genetic counselling can be undertaken by trained professionals from a range of disciplines, those describing themselves as genetic counsellors are specifically trained for the work. A definition of genetic counselling as an activity was produced by the NSGC Taskforce in 2006 and states that 'genetic counselling is the process of helping people understand and adapt to the medical, psychological and familial implications of the genetic contributions to disease. The process includes interpretation, risk assessment, education and counselling. ${ }^{2}$ However, the members of that Task Force deliberately sought to define the activity, rather than the professional role of genetic counsellors. In Europe, the Ad Hoc Genetic Nurse and Counsellor Committee of the European Society of Human Genetics (ESHG) suggested that 'genetic counsellor' should be a protected professional title referring to a health professional who had been educated and trained at Master's level to enable them to develop the core competence defined for the role and to practice according to the Code of Ethics. ${ }^{3}$ This definition has been adopted by the European Board of Medical Genetics, which is responsible for registration of genetic counsellors in Europe. ${ }^{4}$ The key aspects of the role of the European genetic counsellor are presented in Figure 1.

Genetic counsellors may be employed in specialist genetic centres or within other specialist units. Frequently they contribute to patient care as one member of a multi-disciplinary team, for example, in oncology, ${ }^{5}$ ophthalmology, ${ }^{6} \quad$ cardiology, ${ }^{7}$ metabolic clinics ${ }^{8}$ or obstetrics. ${ }^{9}$ The roles of the genetic counsellor (Figure 1) include both information giving and exploration of the client's circumstances and needs. ${ }^{3}$ However, it is not clear whether genetic counsellors fulfil all of the roles ascribed to them, in either specialist genetic clinics or in more mainstream health-care settings. For example, there has long been discussion around whether genetic counsellors adhere to a teaching or counselling model of practice. The 'teaching model' relies far more on information provision to support decision making than exploration of the client's emotional and social needs, whereas use of the 'counselling model' may enhance the exploration of the context of decisions to be made and support adaptation to risk or diagnosis. It could be argued that use of the teaching model reinforces the position of the counsellor as expert; however, those who adhere to this model see information as empowering to clients, whereas those using the counselling model emphasise the relationship between client and counsellor and positive regard for the client as being the tools of empowerment. Meiser et al ${ }^{10}$ undertook a systematic review of studies that involved analysis of actual genetic counselling sessions by genetic health-care providers, including genetic counsellors. The authors concluded that the teaching model appeared to predominate, with counsellors spending much more time speaking during the consultation than clients. However, more positive outcomes for clients were associated with those consultations in which clients were given more opportunities to speak and the counsellor was less dominant. It therefore appears that both information provision and

${ }^{1}$ Faculty of Health and Human Sciences, Plymouth University, Plymouth, UK; ${ }^{2}$ Department of Oncology and Haematology, Hospital of Strasbourg, Strasbourg, France; ${ }^{3}$ Department of Public Health and Caring Science, Uppsala University, Uppsala, Sweden; ${ }^{4}$ School of Health, University of Central Lancashire (UCLan), Preston, UK

*Correspondence: Professor H Skirton, Faculty of Health and Human Sciences, Plymouth University, Drake Circus, Plymouth PL4 8 AA, UK. Tel: +44 1752 586 569 ; E-mail: heather.skirton@plymouth.ac.uk

Received 4 February 2014; revised 12 May 2014; accepted 15 May 2014; published online 11 June 2014 
1. To identify the needs of the individual or family and use an empathic clientcentred approach to the provision of genetic counselling

2. To collect, select, interpret and analyse information (including family and medical history, pedigree, laboratory results and literature) relevant to the delivery of genetic counselling for individuals or families

3. To help people understand and adapt to the medical, psychological, social and familial implications of genetic contributions to disease

4. To assess the chance of disease occurrence or recurrence

5. To provide education about inheritance, testing, management, prevention, resources and research to relevant individuals or families

6. To promote informed choices and psychological adaptation to the condition or risk of the condition

7. To apply expert knowledge to facilitate the individual or family to access the appropriate healthcare resources, including a medical diagnosis and resources for management of the condition. ${ }^{3}(\mathrm{p} 172)$

Figure 1 Role of the genetic counsellor.

sensitive counselling are required to fulfil the role appropriately and maximise benefit to patients.

In order to evaluate the extent to which genetic counsellors fulfil the roles adopted by the European Board of Medical Genetics, we conducted a systematic review of the published relevant scientific evidence.

\section{MATERIALS AND METHODS}

Conducting a systematic review enables the evidence on a particular topic to be gathered, analysed and synthesised. Adherence to a rigorous set of guidelines is essential to ensure rigour and objectivity. We followed the process for systematic reviews developed by the Centre for Reviews and Dissemination, ${ }^{11}$ which involves identification of relevant search terms, selection of studies based on explicit inclusion and exclusion criteria and quality assessment of papers. The research question was 'What is the role of the genetic counsellor?'.

\section{Search strategy}

We initially conducted a search of five relevant electronic databases: Medline, CINAHL, SocIndex, AMED and PsychInfo. Following an initial ad hoc search to determine the relevant search terms, we used the following search terms: 'genetic counsellor' or 'genetic counsellor' and 'role' or 'task' or 'responsibility' or activity' or 'job' or 'profession' and 'service' or 'clinic' or 'hospital' or 'community' (within any part of the text). The search focussed on papers published in English between 1 January 2000 and 30 June 2013 and the search was limited to published articles. Papers were eligible for inclusion if they: (i) were based on research using qualitative, quantitative or mixed methods designs, (ii) included data on roles or clinical responsibilities of genetic counsellors (where the paper reported roles of multiple professions, they were included if data related to genetic counsellors could be extracted from data on other professions) and (iii) focussed on the role of the genetic counsellor in specialist genetic or other clinical settings in any country.

Papers were excluded if they: (i) focussed on patient perceptions of the service, rather than analysis of the genetic counsellor role, (ii) related to comparison of delivery modes for genetic counselling, for example, telephone versus face to face counselling, (iii) related to styles of counselling rather than roles or (iv) were focussed on genetic counsellor education.

As a result of the initial search, we identified 419 potential papers for inclusion. Of these, 63 were duplicates, leaving 356 papers for examination. Further to this process, a handsearch of the indexes of four highly relevant journals for papers published between the relevant dates was undertaken, these were: Journal of Genetic Counseling, American Journal of Medical Genetics, European Journal of Human Genetics and Clinical Genetics. No further papers were identified. After reading the titles of all papers, a further 299 were excluded, leaving a total of 57 papers. The abstracts of these papers were read by two researchers, and a further 40 were excluded on the grounds that they did not fit the exclusion criteria (see Figure 2). All 17 remaining papers were read in full by two researchers, of these seven fitted the criteria for the review. This process is illustrated in the PRISMA flow diagram in Figure 2.

\section{Quality assessment}

Assessment of the quality of studies was undertaken using the tool developed by Kmet et al. ${ }^{12}$ This tool facilitates evaluation of both quantitative and qualitative studies, using two lists of relevant questions. Each paper is scored against each question, a score of 2 is assigned if the quality criterion is met, 1 if partially met and 0 if not met. The total score is then converted to a percentage. Each paper was assessed independently by two researchers and any areas of disagreement were discussed until consensus was reached. The tool developers ${ }^{12}$ do not specify a cutoff point below which papers should be discarded; we decided that a cutoff point of $60 \%$ was appropriate to enable us to exclude poor-quality papers. The range of scores for the included papers was 60-89\%, therefore all were included.

\section{Data abstraction}

Original data from the included studies were abstracted and presented in a table. As there was a diversity of studies and populations, a meta-analysis of the data was not feasible. We therefore conducted a thematic analysis of the data ${ }^{13}$ and present this in narrative form. At least two of the authors were involved in data selection and abstraction at every stage in the review.

\section{RESULTS}

Original data from the included studies are presented in Table 1. Of the seven studies, three were conducted in the United States, three in Australia and one in South Africa. Two studies were undertaken using qualitative methods. ${ }^{14,15}$ Of the other five studies, two involved both analysis of secondary data and a survey, ${ }^{16,17}$ one was based on a retrospective case series ${ }^{18}$ and two were survey based. ${ }^{19,20}$ Cohort sizes ranged from 10 to 76 participants. The themes extracted from the papers were: (1) rationale for using genetic counsellors to provide clinical care, (2) appropriate roles and responsibilities for genetic counsellors and (3) types of conditions that could be included in the genetic counsellor caseload.

The education and training of the genetic counsellors who were the focus of the studies was not mentioned in all papers. In the US papers, Hannig et al ${ }^{16}$ stated that genetic counsellors were licensed in the US state in which the study took place, whereas Powell et $a l^{20}$ and Hines et $a l^{15}$ studied members of the NSGC. It can therefore be assumed that the majority of the genetic counsellors in those studies were educated via a Master's programme in genetic counselling. Hodgson et al $^{14}$ explained that in Australia genetic counsellors undertook a postgraduate diploma in genetic counselling and could be certified by submitting a portfolio of cases to the Board of Censors of the Human Genetic Society of Australasia (HGSA). In that study, five participants were trained as genetic counsellors and one was certified. Similarly, in another Australian study James et al ${ }^{19}$ recruited certified genetic counsellors and associate genetic counsellors. All 10 counsellors in the Australian study by Kromberg et al ${ }^{18}$ were HGSA certified but had a range of backgrounds; five were nurses. Kromberg et $a l^{17}$ described the education of genetic counsellors in South Africa: all undertake a Master's degree in genetic counselling and are able to apply for registration as a genetic counsellor with the Health Professionals Council of South Africa.

\section{Rationale for genetic counsellors to provide clinical care}

Authors stated that there was a need for genetic counsellors to be utilised to provide care because the number of patients seeking genetic health care was growing rapidly and the numbers of available medical geneticists could not cope with the demand; ${ }^{16}$ the increased demand for genetic counsellors was also related to increase in the complexity of cases and the number of laboratory test that were available, for which informed consent was necessary. ${ }^{16}$ Related to this point, Kromberg et all suggested that the role of the genetic 


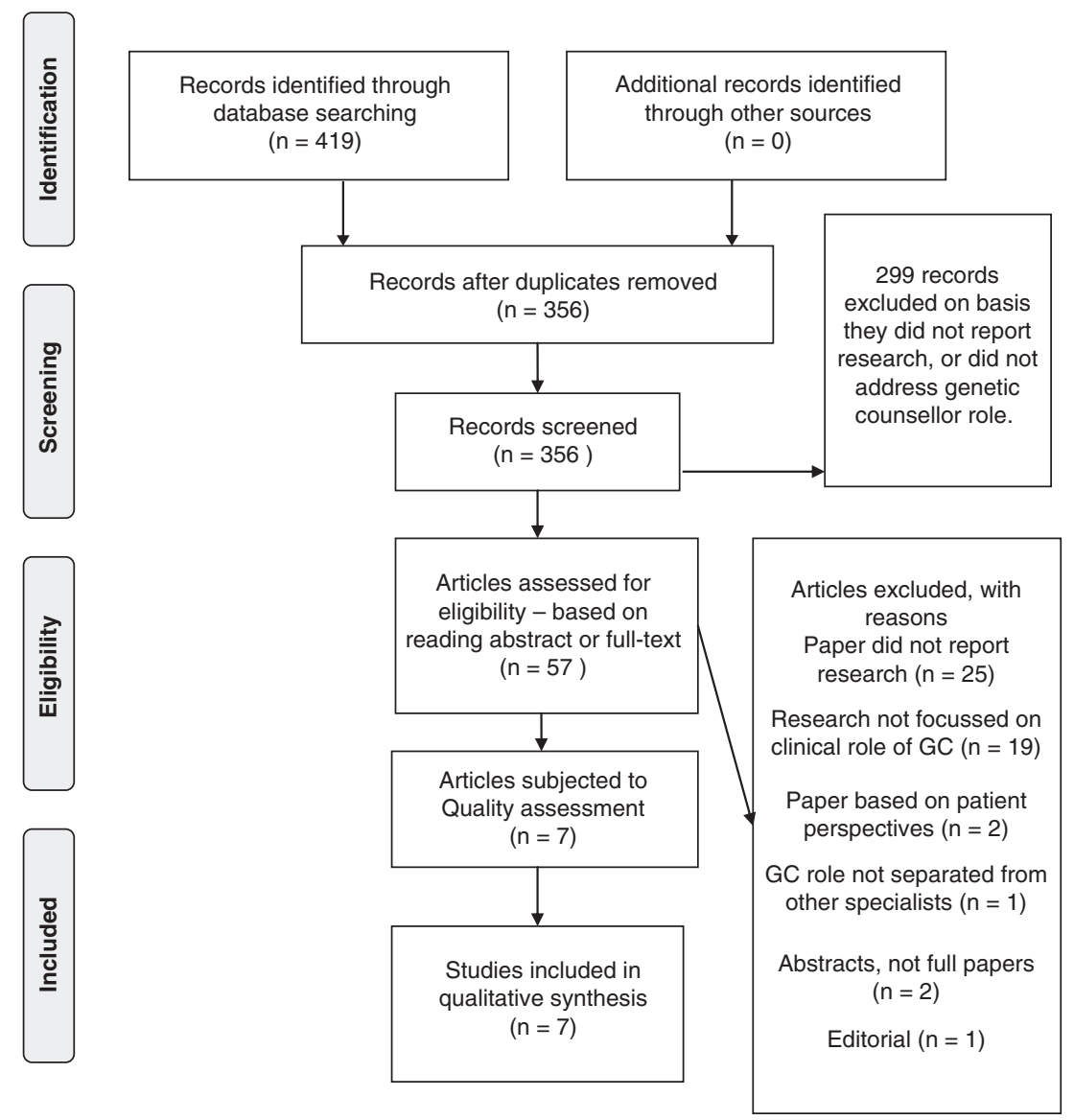

Figure 2 PRISMA flow diagram demonstrating selection of papers.

counsellor would expand further, as pre- and post-test counselling was essential to accompany the increasing number of tests available, particularly for presymptomatic tests. It was claimed that genetic counsellors had more available clinical time than medical geneticists and consultations with genetic counsellors were therefore less pressured. ${ }^{16}$ Powell et al ${ }^{20}$ stated that the skills of the genetic counsellor were useful in public health settings, citing involvement in administering newborn screening programmes as an example. However, with regard to the value placed on genetic counsellors in some settings, it may be significant that the genetic counsellors in the study by Hannig et al ${ }^{16}$ were only allocated clinical space on a day it was not required by others and were unable to charge for their services. This could be important in a health-care system placed on insurance, such as the United States where that study was set.

\section{Appropriate roles and responsibilities for genetic counsellors}

Some authors described the activities undertaken by genetic counsellors in the clinical environment. These included family history taking, ${ }^{16,19}$ pedigree drawing, ${ }^{19}$ risk assessment, ${ }^{16,19}$ discussion of natural history of the condition, ${ }^{16}$ psychosocial impact of the diagnosis, ${ }^{19}$ provision of patient education, ${ }^{15,18,19}$ discussion of options, ${ }^{16}$ addressing ethical issues, ${ }^{15}$ making a psychosocial assessment $^{16}$ and providing psychosocial support. ${ }^{15}$ Other responsibilities perceived to be appropriate for genetic counsellors included providing professional and public education ${ }^{18,20}$ and conducting newborn screening programmes. ${ }^{20}$
Some authors mentioned roles that were not considered appropriate for genetic counsellors to undertake: Hannig et al ${ }^{16}$ expressly stated that examination and management of complex cases was outside the role. However, James et a ${ }^{19}$ found that some respondents did appear to be conducting clinical examinations. The extent to which this happened varied according to the work setting, as $9 \%$ of those working in main units, $20 \%$ of those in metro outreach clinics and $42 \%$ of those in rural outreach communities said they did clinical examinations, but this depended upon the condition or was performed in consultation with a medical geneticist. In an Australian study, ${ }^{18}$ the authors did not explicitly state that diagnosis was not undertaken by genetic counsellors, but did say that the reason that $20 \%$ of cases were seen by medical geneticists alone was because those cases required diagnostic input. Kromberg et al ${ }^{17}$ did not indicate that there were roles that should not be undertaken by genetic counsellors in South Africa, but did stress that emphasis on the prior experience of the counsellor should be considered.

Other authors took a different approach to analysis of roles. For example, in the study of prenatal genetic counselling, Hodgson et al ${ }^{14}$ described the counsellors providing information on the screening test, diagnostic testing, test procedure, risk of miscarriage, possible results and the nature of the decisions to be made by parents. In the same study the interactions between client and counsellor were designated as: risk communication, decision making dialogue and discourse on abortion. Somewhat similarly, Hines et $a^{15}$ organised the responses of their participants into domains labelled information provision, reproductive decision making, psychosocial support and addressing 


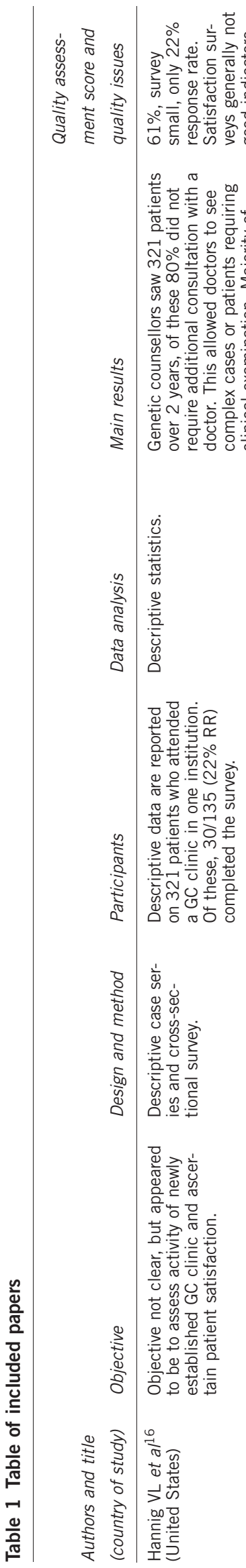

$\stackrel{\circ}{\infty}$

$\stackrel{\circ}{\infty}$

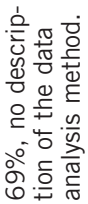

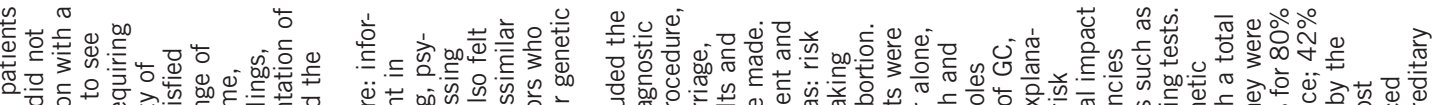

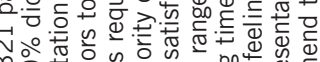

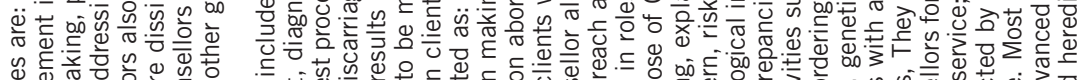

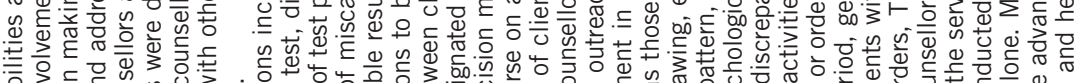

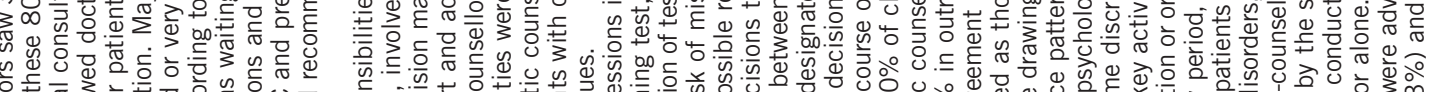

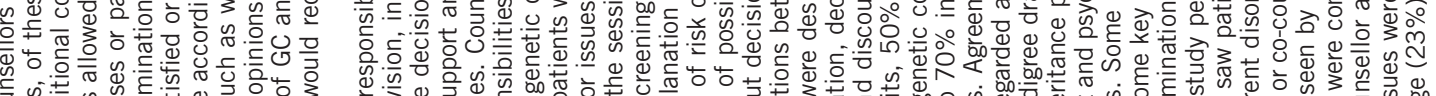
年

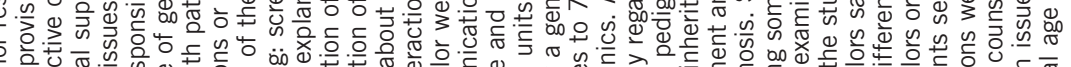

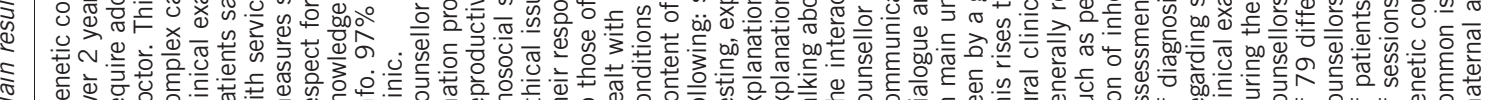
离

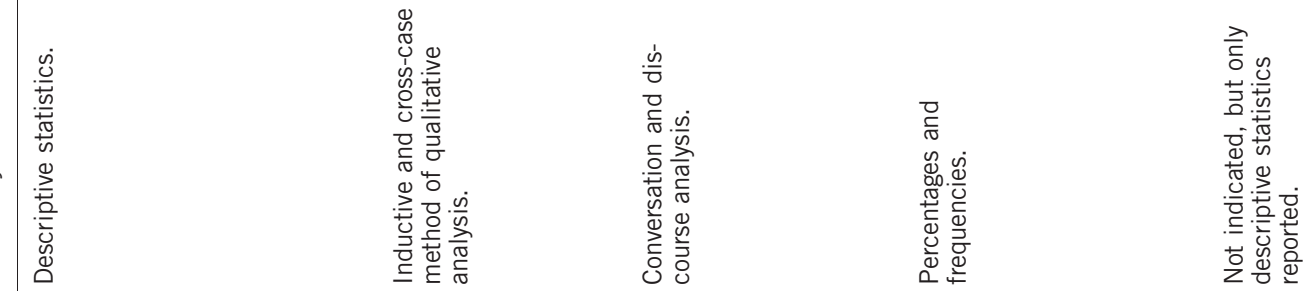

힝.흐뭉

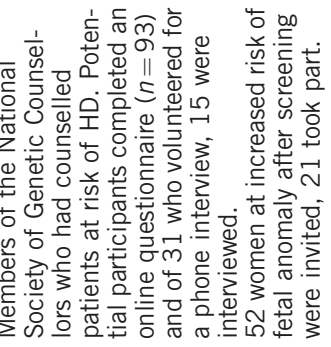

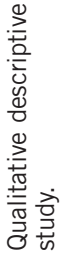

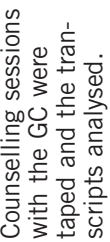

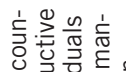

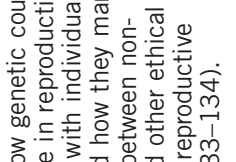

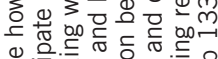

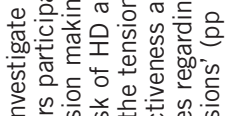

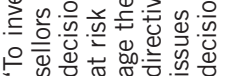

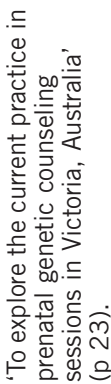

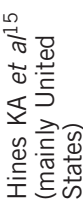

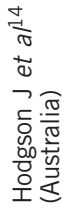

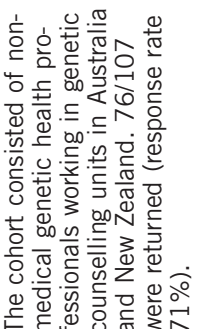

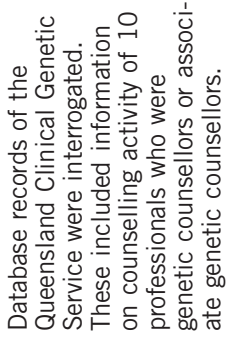

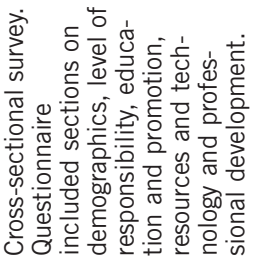
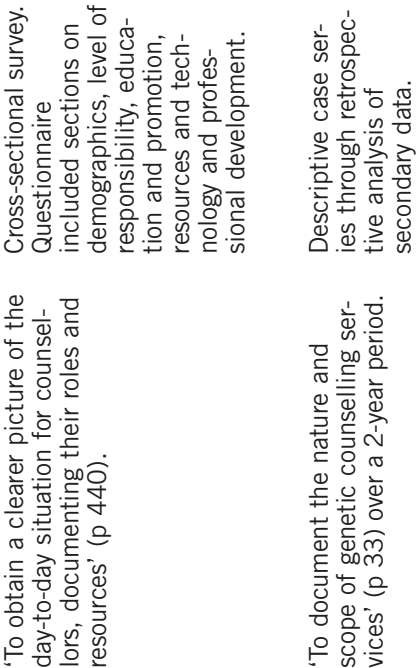

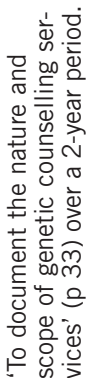

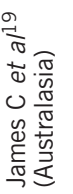




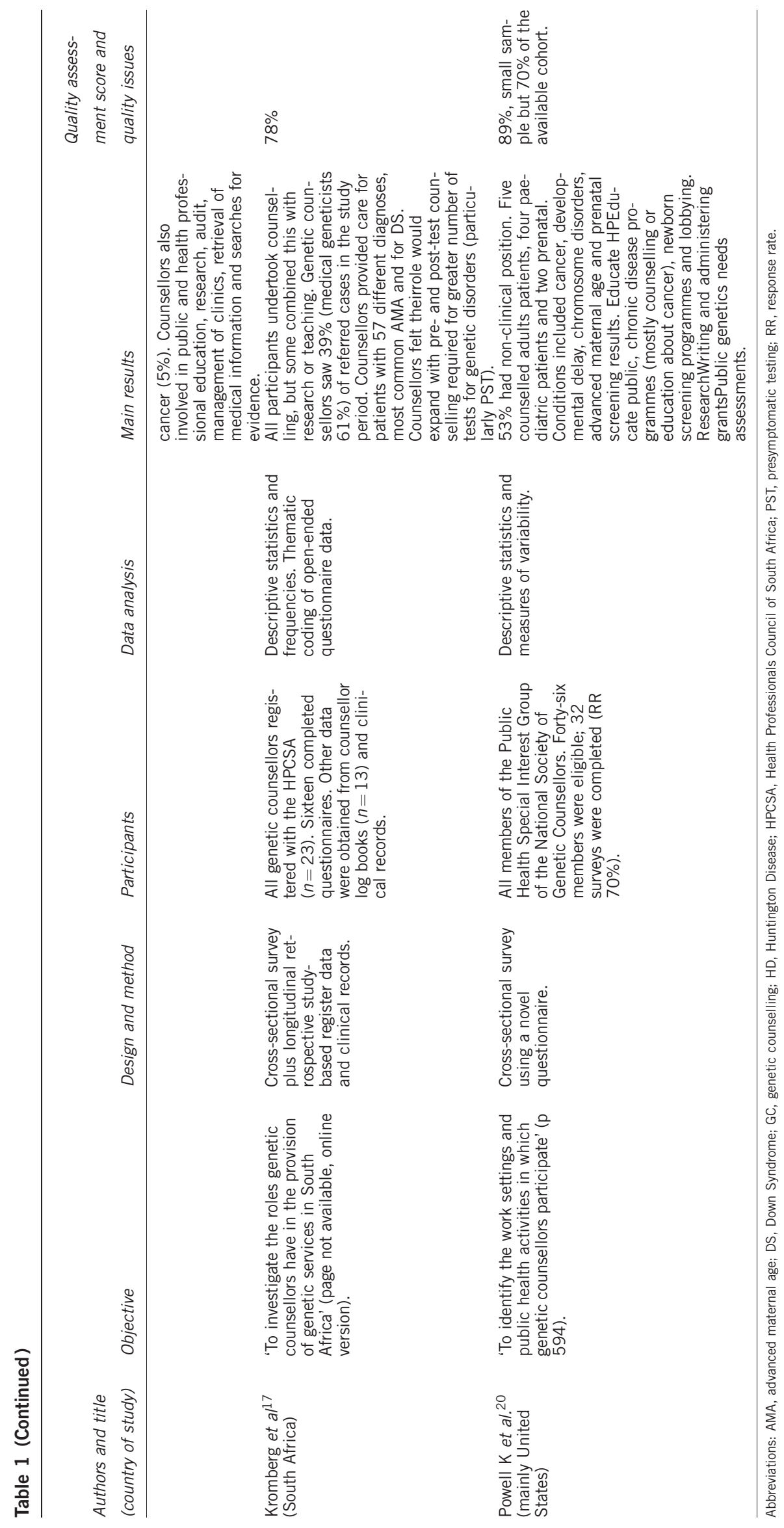


ethical issues. The counsellors in that study offered presymptomatic testing for Huntington Disease, and did express the view that in some ways their service differed from other genetic counselling, for example, they felt that they were at times more directive in the context of counselling for Huntington disease.

\section{Types of conditions that could be included in the genetic counsellor caseload}

It was stated that genetic counsellors could provide care for families affected by or concerned about the following conditions: familial cancer, ${ }^{16-20}$ neurodegenerative conditions ${ }^{16}$ (including offering presymptomatic testing), chromosomal abnormalities ${ }^{16-20}$ (including the sex chromosomes ${ }^{18,20}$ ), multiple miscarriage ${ }^{16,17}$ and single-gene disorders ${ }^{18,20}$ including haemoglobinopathy, ${ }^{16,17}$ cystic fibrosis, ${ }^{16-19}$ metabolic disorders, ${ }^{17,19}$ neurofibromatosis, ${ }^{17,18}$ muscular dystrophy, ${ }^{17,18}$ haemachromatosis ${ }^{19}$ and Huntington disease. ${ }^{15,17,19}$ Counselling for neural tube defect, ${ }^{18,19}$ advanced maternal age ${ }^{17,18,20}$ or abnormal prenatal screening results ${ }^{17,20}$ were also explicitly mentioned by several authors.

Of interest, Hannig et al ${ }^{16}$ stated that the diagnosis should be known in cases of cystic fibrosis, neurogenetic conditions, endocrine disorders and sex chromosome abnormalities. This seems to contradict the claims of Powell et $a l,{ }^{20}$ who cite cases of developmental delay as suitable for counselling by genetic counsellors, and Kromberg et $a l^{17}$ who cite general 'fetal abnormality' cases as suitable for genetic counsellor management.

\section{DISCUSSION}

To ensure rigour, this review was conducted according to the stringent criteria recommended by the Centre for Reviews and Dissemination. ${ }^{11}$ The selection of material for inclusion and the quality assessment were conducted independently by at least two authors. However, we did not search for studies that had not been published in peerreviewed journals, and there may be unpublished data that could have contributed to our understanding of this topic.

Both the Council of Europe ${ }^{21}$ and the Organisation for Economic Co-operation and Development ${ }^{22}$ recommendations on genetic testing emphasise that those considering testing must be provided with relevant information to enable them to give informed consent, and that people providing genetic counselling to accompany testing must have the required educational preparation and training. These points are consistent with the recommendations made by Kariainen et $a^{23}$ in a document produced as part of the EuroGentest project that genetic counselling within the context of genetic testing must be delivered by a person trained to provide it. In a recent survey of members of the NSGC, ${ }^{24} 73 \%$ of the members who responded had completed a Master's degree in genetic counselling, whereas the majority of respondents to a similar survey for the Australasian Society of Genetic Counsellors ${ }^{25}$ had a graduate diploma (41\%) or a Master's degree (31\%). The majority of genetic counsellors in the studies included in this review therefore appear to have been educated at postgraduate level via a specific genetic counselling programme, and all worked in countries where the opportunity for professional registration or certification existed. This confirms the European Board of Medical Genetics stance that education in genetic counselling or genetic nursing at Master's degree level is essential to prepare professionals for practice. ${ }^{4}$

Hannig et al ${ }^{16}$ suggested that the increases in genetic tests, the concurrent need for genetic counselling to accompany those tests and the limitation to the numbers of medical geneticists to see clients has emphasised the need for genetic counsellors to be included in the team providing specialist genetic health-care services. This is in keeping with the standards of genetic counsellor practice in Europe ${ }^{3}$ that have been adopted by the European Board of Medical Genetics and the recommendations for genetic testing practice ${ }^{23}$ accepted by the ESHG, which state that genetic counselling should accompany genetic testing. However, it should be noted that none of the studies in this review were conducted in Europe, and this is an area where research is urgently needed to ensure that genetic counsellor roles are appropriate for this different cultural context.

Although there is general agreement about the core component of the role of the genetic counsellor across studies, the inclusion of a clinical examination of the consultant for diagnostic purposes is included in only one study. ${ }^{19}$ This appears to be controversial, as diagnosis or management of complex cases by genetic counsellors is specifically excluded in another study. ${ }^{16}$ It is possible that conflicting views about clinical examination arise owing to the differences in professional backgrounds of genetic counsellors: those who are also nurses may be trained in some examination skills and feel more confident in performing these. The study in which these skills were included was conducted in Australia, where a proportion of genetic counsellors have nursing backgrounds ${ }^{18}$ and where those in rural or remote locations may be expected to perform examinations. Diagnostic activities based on clinical examination are not mentioned in the European core competencies for genetic counsellors, however, it is clear that genetic counsellors utilise a range of documented evidence to perform genetic diagnoses to provide counselling. For example, a genetic counsellor would use the family history and a report signifying a BRCA1 mutation in an affected family member to make a diagnosis of familial breast and ovarian cancer and counsel the consultant accordingly.

The work of several authors in the area of health psychology has indicated that when an individual is faced with a health threat, adjustment to their circumstances is supported by expression of their emotional responses to the situation. ${ }^{26}$ This would seem to be consistent with the aspect of the genetic counsellor role that states it is based on an empathic client-centred approach. ${ }^{3}$ Enabling and inviting emotional expression could therefore facilitate adaptation and support effective decision making in the context of genetic risk. Roles included in this review include making a psychosocial risk assessment and offering psychosocial support. However, Roter et al ${ }^{27}$ identified four general styles of counsellor behaviour. These were clinical teaching (used by $31 \%$ ), psycho-educational teaching (27\%), supportive counselling (33\%) and psychosocial counselling (14.9\%). Those who used the first three models spoke at least five times as frequently as clients during simulated genetic counselling sessions, whereas even counsellors who utilised a psychosocial counselling model spoke at least four times as often as their clients, indicating that the consultation was highly counsellor oriented. One of the limitations of this study was the use of simulated, rather than genuine clients, and this may have affected both client and counsellor behaviour

The results of this review are interesting when compared with the findings of Ellington et al, ${ }^{28}$ who analysed the content and personal interaction of genetic counselling sessions concerning either prenatal diagnosis or familial cancer risk. The authors found that counsellors spent more time during the session focussing on enabling their clients to express emotional responses (25.49\% of the total time) than they did supporting cognitive processing of the information provided ( $4.23 \%$ of the total time). However, the authors conclude that both responsiveness to client emotion and enabling cognitive processing are necessary to enable clients to process information provided and 
enable them to use it effectively in decision making. The predominance of the 'teaching model' within genetic counselling is certainly confirmed by the studies described above. ${ }^{27,28}$ This may indicate that genetic counsellors are more comfortable with the 'information giving' aspects of their role than they are with eliciting client concerns or providing psychological care. However, as indicated by authors such as Lepore et $a l,{ }^{26}$ this focus on information giving may not be optimal in supporting patients to make decisions relevant to their health care.

Although McCarthy Veach et a ${ }^{29}$ have suggested that the model of health care offered by the genetic counselling practice is somewhat unique, Smets et al ${ }^{30}$ argue that genetics specialists have similar ethos to health professionals operating outside the genetic speciality, and face similar challenges in engaging clients, eliciting the client's agenda and facilitating understanding of relevant concepts. The authors conclude that rather than claim unique skills and approaches, genetic specialists could learn from research undertaken on shared decision making and client/professional communication outside the field.

The findings of this systematic review indicate that where genetic counsellors are utilised in specialist genetic settings, they undertake a significant workload associated with direct patient care and this appears to be acceptable to patients. Notwithstanding that limitation, with the increasing burden on genetic services generally, the results of this review could be used to argue for the increased use of genetic counsellors in countries where they are under-utilised. In addition, the roles undertaken by genetic counsellors in specialist genetic settings could be adapted to integrate genetic counsellors into multi-disciplinary teams in other specialisms.

\section{CONFLICT OF INTEREST}

The authors declare no conflict of interest.

1 Resta RG: Defining and redefining the scope and goals of genetic counseling. Am J Med Genet Part C Semin Med Genet 2006; 142C: 269-275.

2 Resta R, Biesecker B, Bennett RL et al: A new definition of genetic counseling: National Society of Genetic Counselor's Task Force report. J Genet Couns 2006; 15: 77-83.

3 Skirton $\mathrm{H}$, Patch $\mathrm{C}$, Voelckel M-A: Using a community of practice to develop standards of practice and education for genetic counsellors in Europe. J Community Genet 2010; 1: 169-173.

4 European Board of Medical Genetics: Professional and educational standards for genetic counsellors in Europe 2010. Available at: https://www.eshg.org/fileadmin/eshg/ committees/EBMG/EBMGProfessionalAndEducationalStandardsForGeneticCounsellors-July2010.pdf (last accessed 4 February 2014).

5 Bennett C, Burton H, Farndon P: Competences, education and support for new roles in cancer genetics services: outcomes from the cancer genetics pilot projects. Fam Cancer 2007; 6: 171-180.
6 Cordier C, Taris N, De Pauw A, Sobol H, Philip N, Voelckel MA: French professionals in genetic counselor careers. J Genet Couns 2013; 22: 844-848.

7 Ingles J, Lind JM, Phongsavan P, Semsarian C: Psychosocial impact of specialized cardiac genetic clinics for hypertrophic cardiomyopathy. Genet Med 2008; 10: 117-120

8 Hartley J, Greenberg C, Mhanni A: Genetic counseling in a busy pediatric metabolic practice. J Genet Couns 2011; 20: 20-22.

9 Pergament E, Pergament D: Reproductive decisions after fetal genetic counselling Best Pract Res Clin Obstet Gynaecol 2012; 26: 517-529.

10 Meiser B, Irle J, Lobb E, Barlow-Stewart K: Assessment of the content and process of genetic counseling: a critical review of empirical studies. J Genet Couns 2008; 17: 434-451.

11 Centre for Reviews and Dissemination: Systematic Reviews. York, UK: CRD, 2009.

12 Kmet LM, Lee RC, Cook LS: Standard quality assessment criteria for evaluating primary research papers from a variety of fields. Alta Herit Found Med Res 2004; 13: $1-11$.

13 Braun V, Clarke V: Using thematic analysis in psychology. Qual Res Psychol 2006; 3: 77-101.

14 Hodgson J, Gillam L, Sahhar M, Metcalfe S: "Testing times, challenging choices": an Australian study of prenatal genetic counseling. J Genet Couns 2010; 19: 22-37.

15 Hines KA, Veach PM, LeRoy BS: Genetic counselors' perceived responsibilities regarding reproductive issues for patients at risk for Huntington disease. J Genet Couns 2010; 19: 131-147.

16 Hannig V, Cohen M, Pfotenhauer J, Williams M, Morgan T, Phillips J 3rd: Expansion of genetic services utilizing a general genetic counseling clinic. J Genet Couns 2013; 23: 64-71.

17 Kromberg JGR, Wessels T-M, Krause A: Roles of genetic counselors in South Africa. J Genet Couns 2013; 22: 753-761.

18 Kromberg JGR, Parkes J, Taylor S: Genetic counselling as a developing healthcare profession: a case study in the queensland context. Aust J Prim Health 2006; 12 33-39.

19 James C, Worthington S, Coliey A: The genetic counseling workplace-an Australasian perspective. A National Study of Workplace Issues for Genetic Counselors and Associate Genetic Counselors. J Genet Couns 2003; 12: 439-456.

20 Powell KP, Hasegawa L, McWalter K: Expanding roles: a survey of public health genetic counselors. J Genet Couns 2010; 19: 593-605

21 Council of Europe: Additional Protocol to the Convention on Human Rights and Biomedicine concerning Genetic Testing for Health Purposes 2008. Council of Europe Treaty Series 203 (last accessed 27 November 2008).

22 Organisation of Economic Co-operation and Development: OECD Guidelines for Quality Assurance in Molecular Genetic Testing 2007. Available at: http://www.oecd.org/ science/biotech/38839788.pdf (last accessed 7 April 2014).

23 Kääriäinen $\mathrm{H}$, Hietala $\mathrm{M}$, Kristoffersson $\mathrm{U}$ et al: Recommendations for genetic counselling related to genetic testing. Available at: http://www.eurogentest.org/ fileadmin/templates/eugt/pdf/guidelines of GC final.pdf (last accessed 4 April 2014).

24 National Society of Genetic Counselors: Professional Status Survey Executive Summary 2012. Available at: http://nsgc.org/p/cm/ld/fid=68 (last accessed 4 April 2014).

25 Australian Survey Research Group Pty Ltd: Australasian Society of Genetic Counsellors 2012 Census. Available at: http://www.hgsa.org.au/documents/item/419 (last accessed 4 April 2014).

26 Lepore SJ, Ragan JD, Jones S: Talking facilitates cognitive-emotional processes of adaptation to an acute stressor. J Pers Soc Psychol 2000; 78: 499-508.

27 Roter D, Ellington L, Erby LH, Larson S, Dudley W: The Genetic counseling video project (GCVP): models of practice. Am J Med Genet Part C Semin Med Genet 2006; 142C: 209-220.

28 Ellington L, Kelly KM, Reblin M, Latimer S, Roter D: Communication in genetic counseling: cognitive and emotional processing. Health Commun 2011; 26: 667-675.

29 McCarthy-Veach P, Bartels D, LeRoy B: Elements of a model of practice for genetic counseling: synthesis of a consensus conference. Twenty-fifth Annual Education Conference of the National Society of Genetic Counselors. J Genet Couns 2007; 16: 26-26.

30 Smets $\mathrm{E}$, van Zwieten M, Michie S: Comparing genetic counseling with non-genetic health care interactions: two of a kind? Patient Educ Couns 2007; 68: 225-234. 